\title{
Effective Use of Online Tools to Prepare Students for Competitive Examinations
}

\author{
Ms. Varsha T.Lokare', Mrs. Gautami Shingan ${ }^{2}$, Mr. Prakash Jadhav ${ }^{3}$, Dr. N.V.Dharwadkar ${ }^{4}$ \\ ${ }^{1}$ Department of Computer Science \& Engineering, Rajarambapu Institute of Technology, Sakharale, Maharashtra. \\ ${ }^{2}$ Department of Computer Science \& Engineering, Rajarambapu Institute of Technology, Sakharale, Maharashtra. \\ ${ }^{3}$ Department of Mechanical Engineering, Rajarambapu Institute of Technology, Sakharale, Maharashtra. \\ ${ }^{4}$ Department of Computer Science \& Engineering, Rajarambapu Institute of Technology, Sakharale, Maharashtra. \\ ${ }^{1}$ varsha.lokare@ ritindia.edu \\ 2gautami.shingan@ ritindia.edu \\ 3 prakash.jadhav@ ritindia.edu \\ ${ }^{4}$ nagaraj.dharwadkar@ ritindia.edu
}

\begin{abstract}
To prepare students for various competitive examinations like GATE, GRE etc it is a challenging task as it requires basic understanding of the courses. Also it needs lots of practice to solve complex problems. So, in this paper the use of three online tools: Gate Test series, Answer Garden and Polls Everywhere is been described for the course operating system. As Operating System course has higher weight-age in various competitive examinations like GATE. So, we choose this course as a case study to apply online tools. Finally the comparative analysis has been done for MCQ-Test1 marks where these tools were not used and MCQ-Test2 which was conducted after applying these tools.

Keywords: Gate Test series, Answer Garden and Polls Everywhere, Operating System.
\end{abstract}

\section{INTRODUCTION}

The basic understanding of the core courses is necessary to get success in competitive examinations. It has been observed that traditional teaching methodologies were not that much helpful to get desired output. Hence there is a need of some online tools that prepare students for such examinations. In classroom teaching if we incorporate that tools it will be beneficial for the students to better understand the course in terms of questionnaires asked in competitive exams like GATE and GRE. Many researchers and academicians have already applied different online tools $[1,2]$ to teach various courses. In this paper the detail flow of usage of three tools namely Gate-Test- series, Answer Garden and Polls Everywhere is been given. These tools have been applied in classroom itself during teaching the course Operating system (OS). In the next sections the description of each tool along with application in OS course is been given. Finally in experimental section the comparative analysis of Test 1 and Test 2 marks is done and in last section concluding remarks were given.

\section{TOOL1: GATE TEST SERIES [3]}

This tool is available online and it is free of cost, it covers all discipline courses. The below is the web link mentioned: https://gatetestseries.in/cs-gate-operating-system/

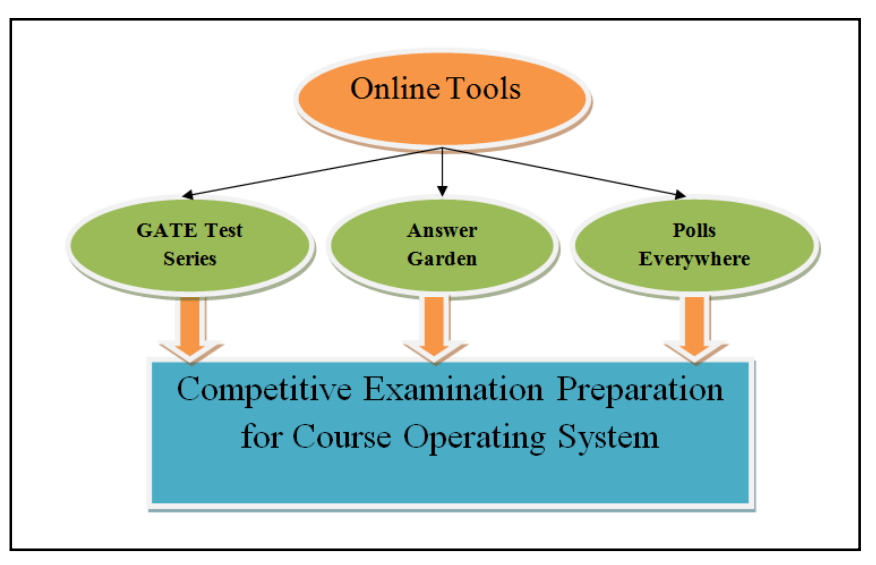

Figure1: Online Tools used for Operating System Course Topic: Process Management Objectives:

1. To understand the concept of process management

2. To able to solve objective questions based on GATE exam

Outcomes:

1. Student should able to solve GATE exam based questions

Steps:

1. Explain the concept of process management with suitable examples (20 min)

2. Tell students to open below link on their mobile: (2min) https://gatetestseries.in/cs-gate-operating-system/processmanagement-1/pm1-online-test-1/

3. Tell students to Appear for online Test and answer for all questions (15min)

4. Tell students to save the screen shot of result ( $2 \mathrm{~min})$

5. Tell to click on view explanation Tab and go through the description of the solution (10 $\mathrm{min}$ )

6 . Then click on Restart Test and reappear the same online test (5min)

7. Now tell them to save the screen shot of the second result. (2min)

8. Upload both result sheets on moodle (2min) 
Journal of Engineering Education Transformations, Volume 33, January 2020, Special issue, eISSN 2394-1707 [ Moodle: a free open source course management system]

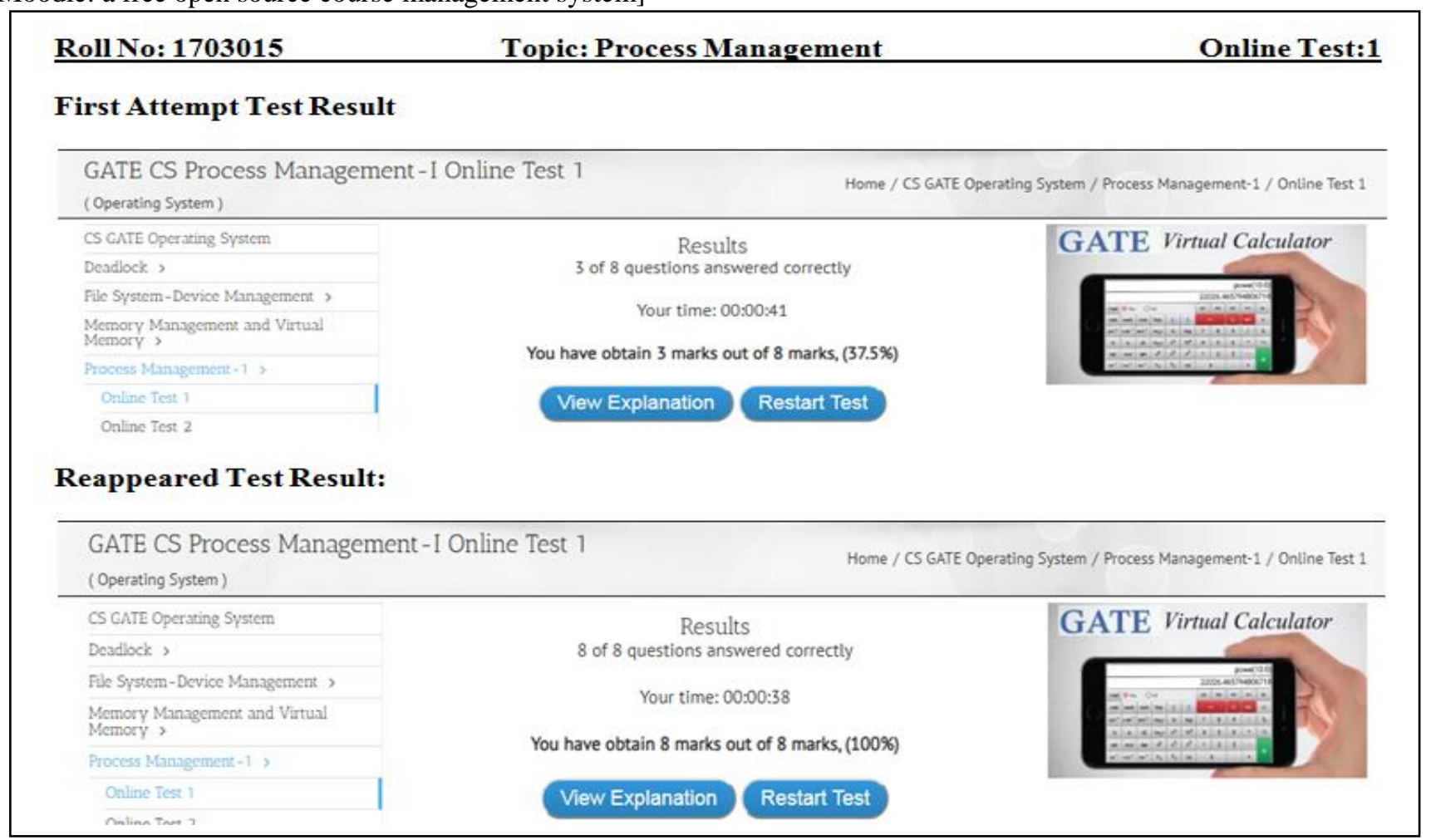

Figure2: Template to upload on Moodle for GATE-TEST-Series Activity

\section{TOOL2: ANSWER GARDEN}

Answer Garden[4] is the online tool used for checking the overall class understanding. It is available on following web link: https://answergarden.ch/create/

\section{Teachers Role:}

1. Teacher should create question on above mentioned link in Topic Tag

2. Teacher should also set mode as a Classroom and Answer length either 20 or 40 characters.

3. Admin Password and Reminder Email Tags are optional 4. Set Spam Filter Tag OFF and choose case for answer either lowercase or uppercase or no change

5. Add duration for Add Local Discoverability 1 hour, 1 day or 1 week or hidden.

6. Finally click on create that create your own Answer Garden: https://answergarden.ch/1008450

\section{Students Role:}

1. Open link: https://answergarden.ch/1008450

2. Type answer and click on Submit. (5 min)

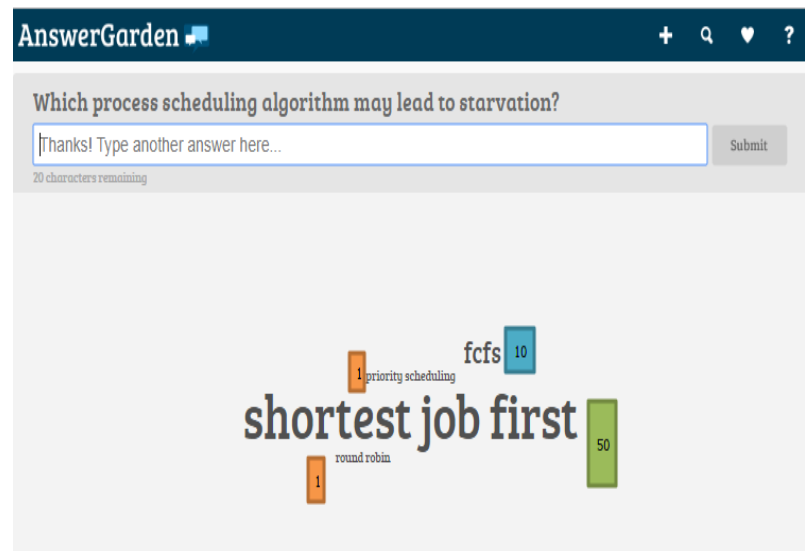

Figure3: Resultant window of Answer Garden activity

As shown in figure3, resultant window will appear that can be used to analyse the understanding of the concept. Here about 50 students have answered Shortest Job First algorithm, which is the correct answer while 10 students were written FCFS, 1 student: Priority scheduling and 1 student Round Robin. Hence, from this statistics we can say that 50 students out of 62 had given correct answer in other words; around $80.64 \%$ students have understood the concept. This tool is helpful to get instant feedback of understanding of the topic within classroom itself. It is also helpful to check the feedback of different innovative teaching learning methodologies. 


\section{TOOL3: POLLS EVERYWHERE}

Polls Everywhere[5] is another online tool which has been applied to check the understanding of the concept within classroom itself. It also not require any registration at user end to participate in quizzes. It collects live responses from the students based on the Multi Choice Questions.

\section{Teachers Role:}

1. Register on https://www.polleverywhere.com/
3. Type Question with Options

4. Click on create

5. Share the below link with students:

\section{Students Role:}

\section{PollEv.com/varshalokare996}

1. Open above shared link

2. Click on response

As shown in Figure4, the live responses can be collected and used to analyse the students understanding.

2. Log in and select polls/ Multiple Choice

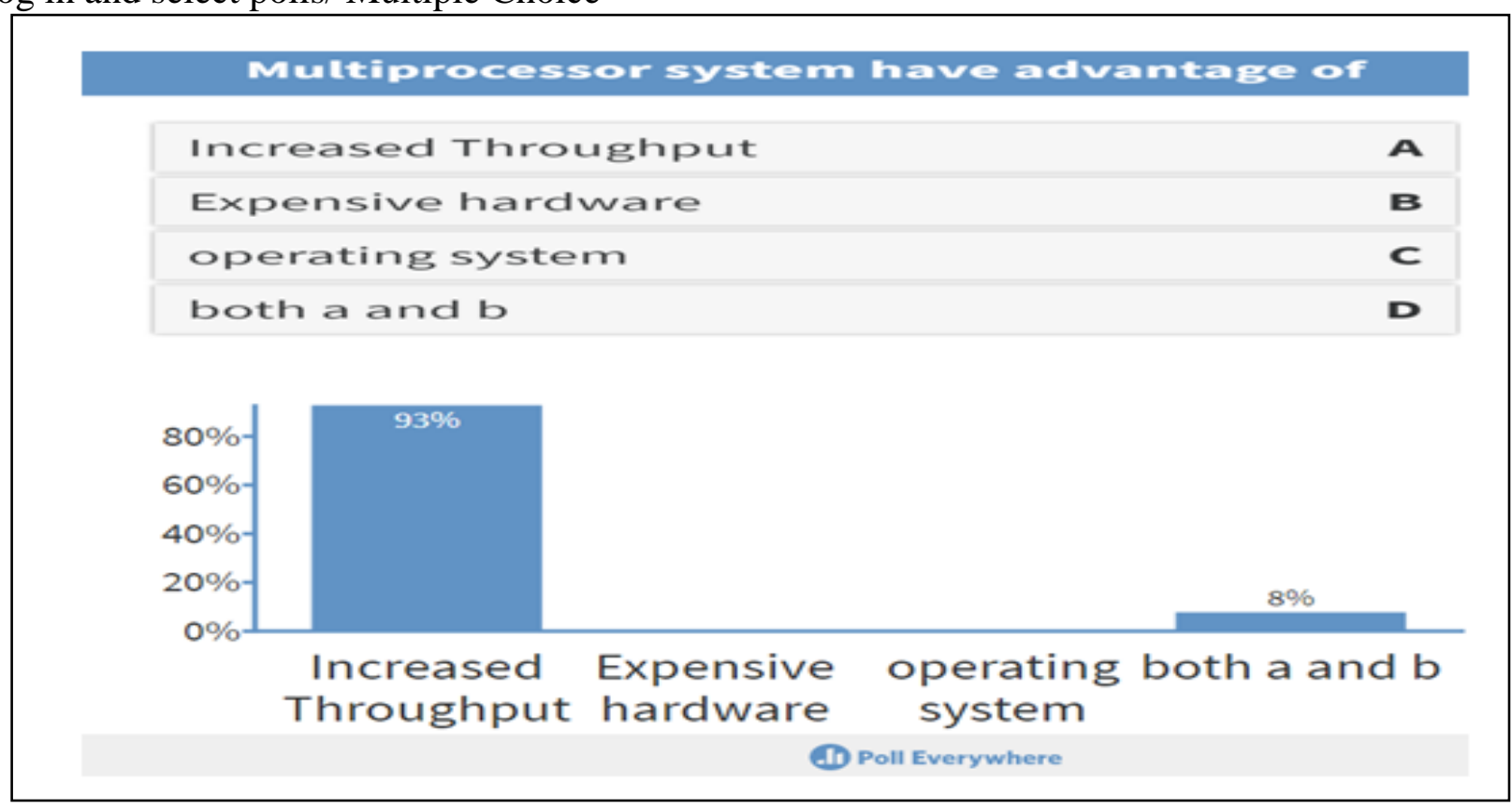

Figure 4: Resultant window of Poll Everywhere Activity

\section{RESULT ANALYSIS}

The above mentioned online tools namely Gate Test series, Answer Garden and Polls Everywhere were applied during classroom teaching for Third Year B.Tech Computer Engineering students ( course name: Operating System) at Rajarambapu Institute of Technology, Sakharale. The comparative analysis is been carried out between the marks of Objective Test (MCQ-Test1) and MCQ-Test2. There were no any online tool was applied before MCQ-Test1 and above mentioned tools was applied after that and then MCQ-Test2 was conducted. The complexity level of the questions asked in MCQ-Test2 was little bit more as compared to MCQ-Test1. Here the analysis of marks of total 70 students is been carried out before applying tools(MCQ-Test1) and after applying tools (MCQ-Test2).

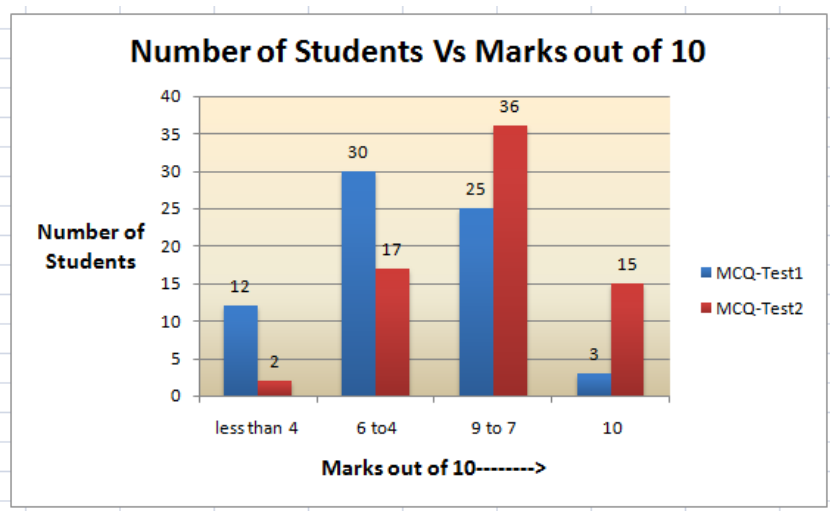

Graph1: Result Analysis of MCQ-Tests

As shown in Graph1 and Table1, it is observed that there is improvement in the number of student' those have secured 10 out of 10 marks. There are around 12 more students got 10 out of 10

marks after applying online tools activity in the classroom. Also there is decrease (from 12 to 2 ) in the number of students those have secured below 4 marks and marks in the range of 6 to 4 . There is also improvement in the range of 9 to 7 marks from 25 to 36. 
Table1: Marks Secured by Students in MCQ-1 and MCQ-2

\begin{tabular}{|l|l|l|l|l|}
\hline \multirow{2}{*}{} & \multicolumn{4}{|c|}{ Number of students secured Marks out } \\
\cline { 2 - 5 } & $\begin{array}{l}\text { Less } \\
\text { than } 4\end{array}$ & 6 to 4 & 9 to 7 & 10 \\
\hline $\begin{array}{l}\text { MCQ- } \\
\text { Test1 }\end{array}$ & 12 & 30 & 25 & 03 \\
\hline $\begin{array}{l}\text { MCQ- } \\
\text { Test2 }\end{array}$ & 02 & 17 & 36 & 15 \\
\hline
\end{tabular}

Many Authors have used different innovative Teaching Learning methodologies $[6,7,8,9]$ in the literature.

\section{CONCLUSION}

The effective usage of online tools namely Gate Test series, Answer Garden and Polls Everywhere is been demonstrated to teach Operating system course. The description of each tool along with its application in few topics of OS course is highlighted in this paper. It has been observed that the students understanding of respective topic is been improved as they were able to solve objective questions asked in various competitive examinations like GATE. Also the feedback has been taken after conducting these activities that represents that many of the students around $90 \%$ to $94 \%$ were interested in taking part in such type of activity.

\section{REFERENCES}

[1] Michelle J. Eady and Lori Lockyer,'Tools for learning: technology and teaching strategies", University of Wollongong, 2013.

[2] Nik Peachey, book: "Digital Tools for Teachers", Peachy Publications, 2018.

[3]Web link: https://gatetestseries.in/cs-gate-operating- system/

[4] https://answergarden.ch/

[5] https://www.polleverywhere.com/

[6] Mr. Prakash M. Jadhav and Ms. Varsha T. Lokare, "A Holistic Approach for Teaching Data Structure Course in the department of Information Technology", Journal of Engineering Education Transformations, 2017.

[7] Gautami G Shingan, Bharati K Ugale,"A Holistic Approach for Teaching Design and Analysis of Algorithms Course in the Department of Computer Engineering", Journal of Engineering Education Transformations, 2018.

[8]Varsha T Lokare, Prakash M Jadhav, Snehal S Patil,"An Integrated Approach for Teaching Object Oriented Programming $(\mathrm{C}++)$ Course", Journal of Engineering Education Transformations, 2018.

[9] Bharati K Ugale, Gautami G Shingan,"A Novel Approach to Improve Logical and Critical Thinking through Collaborative Learning and Using Visualization Tools", Journal of Engineering Education Transformations, 2018. 